\title{
O PNAE como estratégia para construção de novas lógicas de produção e consumo de alimentos no Rio Grande do Sul
}

\section{PNAE as a strategy for building new food production and consumption logics in Rio Grande do Sul}

\author{
Etho Roberio Medeiros Nascimento ${ }^{1}$ \\ Amália Leonel Nascimento ${ }^{2}$ \\ Luciana Dias de Oliveira ${ }^{3}$
}

Nos últimos anos, se observou a intensificação do processo de modernização da agricultura e o aprofundamento das crises sociais nos sistemas agroalimentares. Em meio a esse fenômeno, se consolidou o modelo de transição nutricional com a difusão do consumo de alimentos ultraprocessados, resultando na elevação da insegurança alimentar. Nesse cenário, cresce o apelo de novas estratégias de produção, consumo e comercialização de alimentos, com destaque para a promoção de modelos regionais sustentáveis, com a oferta de alimentos frescos e livres de agrotóxicos; retomada da ação estatal por meio de políticas públicas; e inclusão de agricultores familiares nos mercados agrícolas. Assim, o Programa Nacional de Alimentação Escolar (PNAE), por meio das abordagens de Segurança Alimentar e Nutricional (SAN) e Direito à Alimentação Adequada (DHAA), estimula a compra de no mínimo 30\% da agricultura familiar para fornecimento de alimentos à alimentação escolar. Tal iniciativa tem por objetivo fornecer uma alimentação saudável e sustentável aos escolares da rede pública, além de promover a inclusão socioprodutiva e dinamização econômica de agricultores familiares por meio das compras institucionais. Com isso, o presente trabalho tem por objetivo descrever os resultados obtidos pelo monitoramento e assessoria técnica às Entidades Executoras (EEx) do Rio Grande do Sul (RS), realizada pelo Centro Colaborado em Alimentação e Nutrição Escolar (CECANE), nos anos de 2016 a 2018. A fonte dos dados foi baseada na metodologia da assessoria, definida pelo CECANE/FNDE. Todos os dados foram coletados por meio de questionários semiestruturados, com o objetivo de realizar um diagnóstico sobre a gestão do PNAE nos municípios. Como resultados, temos que no presente período foram realizadas assessorias a 102 municípios, o que abrange $20,5 \%$ do total de municípios do estado. Destes municípios, $67,3 \%$ atingem o percentual mínimo de $30 \%$ de compra da agricultura familiar. De uma maneira geral, a porcentagem de municípios que compram acima de $30 \%$ da agricultura familiar esteve próxima à média do estado $(71,2 \%)$ e superior à média nacional (24,84\%), com aumento dos municípios que realizam a compra. A maior concentração desses municípios $(56,6 \%)$ também incluiu o tema da alimentação saudável nos projetos político-pedagógicos das escolas, e 85\% promoviam ações de educação alimentar, abordando os temas de SAN, DHAA e utilização de alimentos orgânicos e conscientização do consumo de ultraprocessados. Além disso, observa-se o aumento das compras institucionais de produtos orgânicos ou em transição agroecológica. Logo, estes dados denotam que a compra da agricultura familiar contribui com a oferta e o consumo de alimentos saudáveis no ambiente escolar, causando impacto direto nas realidades locais a partir da dinamização dos 
mercados da agricultura familiar e aproximação entre produtores e consumidores finais, compondo uma estratégia alternativa aos sistemas de produção industrial.

Palavras-chave: PNAE; alimentação escolar; segurança alimentar e nutricional.

Keywords: PNA; school feeding; food and nutrition security.

1 Doutorando em Desenvolvimento Rural pela Universidade Federal do Rio Grande do Sul.

2 Doutora em Desenvolvimento Rural pela Universidade Federal do Rio Grande do Sul.

3 Prof. Dra. do Curso de Nutrição da Universidade Federal do Rio Grande do Sul. 